\title{
Erratum to: Dependence of the Spin-Wave Resonance Spectra in Ferrite-Garnet Films on the Microwave Field Frequency and Damping Parameter
}

\author{
A. M. Zyuzin ${ }^{a, *}$, M. A. Bakulin ${ }^{a}$, S. V. Bezborodov ${ }^{a}$, V. V. Radaikin ${ }^{a}$, and S. N. Sabaev ${ }^{a}$ \\ ${ }^{a}$ Ogarev Mordovia State University, Saransk, 430005 Russia \\ *e-mail: zyuzin.am@rambler.ru \\ Received October 28, 2019
}

DOI: $10.1134 /$ S1063776119100261

The surname of the first author should read Zyuzin.

The original article can be found online at https://doi.org/10.1134/S1063776116020230 